LETTER • OPEN ACCESS

The need for coordinated transdisciplinary research infrastructures for pollinator conservation and crop pollination resilience

To cite this article: Ignasi Bartomeus and Lynn V Dicks 2019 Environ. Res. Lett. 14045017

View the article online for updates and enhancements. 


\title{
LETTER
}

CrossMark

OPEN ACCESS

RECEIVED

6 November 2018

ACCEPTED FOR PUBLICATION

5 March 2019

PUBLISHED

17 April 2019

Original content from this

work may be used under

the terms of the Creative

Commons Attribution 3.0

licence.

Any further distribution of this work must maintain attribution to the

author(s) and the title of

the work, journal citation

and DOI.

\section{The need for coordinated transdisciplinary research infrastructures for pollinator conservation and crop pollination resilience}

\author{
Ignasi Bartomeus ${ }^{1}$ (D) and Lynn V Dicks ${ }^{2}$ \\ 1 Estación Biológica de Doñana (EBD-CSIC), Sevilla, Spain \\ 2 School of Biological Sciences, University of East Anglia, Norwich NR4 7TJ, United Kingdom \\ E-mail: nacho.bartomeus@gmail.com \\ Keywords: bees, biodiversity, global change, ecosystem services, monitoring, agroecosystems
}

\begin{abstract}
There is a growing concern about the status and trends of animal pollinators worldwide. Pollinators provide a key service to both wild plants and crops by mediating their reproduction, so pollinator conservation is of fundamental importance to conservation and to food production. Understanding of the extent of pollinator declines is constrained by the paucity of accessible data, which leads to geographically- and taxonomically-biased assessments. In addition, land conversion to agriculture and intensive agricultural management are two of the main threats to pollinators. This is paradoxical, as crop production depends on pollinators to maximize productivity. There is a need to reconcile conservation and ecosystem service provision in agroecosystems. These challenges require coordinated transdisciplinary research infrastructures. Specifically, we need better research infrastructures to (i) describe pollinator decline patterns worldwide, (ii) monitor current pollinator trends, and (iii) understand how to enhance pollinator numbers and pollination in agroecosystems. This can be achieved, first, by redoubling the efforts to make historical data on species occurrences, interactions and traits openly available and easy to integrate across databases. Second, by empowering citizen science to monitor key pollinator species in a coordinated way and standardizing, consolidating and integrating long term collection protocols both in natural and agricultural areas. Finally, there is a need to develop multi-actor, localised research infrastructures allowing integration of social, economic and ecological approaches in agriculture. We illustrate how decentralized infrastructures can accelerate the process of co-producing research and integrating data collection across scientists, managers, members of the public, farmers and disciplines. The time is ripe to harness the power of coordinated research infrastructures to understand and mitigate pollinator declines.
\end{abstract}

\section{Introduction}

Over the past few years there has been an everincreasing concern about generalized pollinator declines. Research on this topic has also increased substantially and our knowledge about the causes and consequences of the actual loss of pollinators has reached an important maturity (Goulson et al 2015, Potts et al 2016). However, the knowledge gained so far has been mainly fragmented and difficult to collate and combine, making it difficult to integrate and reach generality. One of the limiting factors to understanding the extent of pollinator decline and its consequences for ecosystem functioning is still the paucity of data available, which leads to geographically- and taxonomically-biased assessments (Archer et al 2014). We believe that in order to move forward, we need to promote existing coordinated research infrastructures and to develop new decentralized integrative infrastructures. These infrastructures will allow us to unveil the importance of pollinators, to understand their main threats and the consequences of their population declines for ecosystems, and to develop realistic, evidence-based responses.

Pollinators are a diverse group of animals, potentially responsible of reproduction of more than $80 \%$ of plant species worldwide (Ollerton et al 2011). Bees are generally considered the most important pollinators, 
especially for crops (Klein et al 2007, Potts et al 2016). However, many other animals provide pollination services, including other groups of insects like Coleoptera, Lepidoptera, Diptera and non-bee Hymenoptera (Rader et al 2016). In addition, birds, bats, rodents and even lizards are pollinators of many plants, especially at lower latitudes (Winfree et al 2011, Ollerton 2017, Ratto et al 2018). This high diversity of species involved in pollination is the first barrier to studying the extent of pollinator declines, especially given that even the most basic natural history and taxonomy of pollinator species is often unknown. Although there is clear evidence of declines especially in certain groups and regions (Bartomeus et al 2013, Carvalheiro et al 2013, Nieto et al 2014), we do not know the population trends for most pollinator species.

The second barrier to understanding pollinator declines is that the principal causes of decline are varied and can act synergistically. The main cause of the decline of pollinators is probably loss of habitat. More than $40 \%$ of the ice-free land surface is modified by man, especially for agricultural use (Ellis et al 2010). Many pollinators cannot thrive in these modified environments because they cannot find sufficient food or nesting resources (Kennedy et al 2013). Among the transformed habitats, agroecosystems deserve a special mention. Some species of pollinator may find resources in these environments, but there they are exposed to a wide variety of agrochemicals. The threats do not come only from insecticides, such as neonicotinoids (Rundlöf et al 2015), but pollinating insect populations are also affected by fungicides, which eliminate their microbial flora, and by herbicides, which reduce floral resources (Potts et al 2016). This is paradoxical, as crop production highly depends on pollinators for maximizing productivity. To support sustainable production of insect-pollinated crops, it is necessary to reconcile conservation and ecosystem service provision in agroecosystems (Garibaldi et al 2013).

Climate change also affects pollinators. For example, the activity period of many bees has advanced by two weeks compared to 50 years ago (Bartomeus et al 2011) and the distribution range of bumble bees has decreased in Europe and the United States (Kerr et al 2015). Another cause of anthropogenic origin is the introduction of exotic species in an increasingly globalized world. These exotic species can compete with the native pollinators and bring with them new pathogens. For example, the near disappearance of the bumblebee Bombus affinis in the United States is attributed to the introduction of exotic pathogens (Cameron et al 2011), while the rapid decline of Bombus dahlbohmii in Argentina is a result of invasion by the European species B. terrestris (Aizen et al 2018).

Understanding and mitigating these pressures requires a coordinated approach and the use of optimized research infrastructures for a number of reasons. First, human induced rapid environmental change is happening at global scales and needs to be understood and tackled at global scales. Second, these pressures are of different origin and happening simultaneously. Hence, we need to promote interdisciplinary approaches that foster knowledge transfer among different domains such as conservation biology, taxonomy, toxicology or socio-economy. Only by helping to permeate the borders of scientific disciplines can we attempt to solve a complex multidomain problem. To date there have been very few coordinated research infrastructures specifically oriented towards generating research that seeks to understand and respond to pollinator decline, but fortunately these are emerging rapidly. Some of these infrastructures are larger initiatives with general conservation goals, which can be adapted or used to study pollinator declines. Other specific infrastructures are emerging in the form of monitoring programmes focused on pollinators, led by key institutions or governments.

A feature of most current research infrastructures relevant to the pollinator problem is that they are centralized at an institution or organization. These central infrastructures include, for example, infrastructures to monitor particular environments (e.g. Long Term Ecological Research Network; LTER; https://ilter. network/) or of infrastructures to centralize data curation (e.g. Global Biodiversity Information Facility (GBIF); www.gbif.org). They are highly valuable for specific tasks. However, they are unlikely to solve one of the main barriers we face in tackling environmental issues, which is a lack of communication and coordination among a large fraction of actors, for example through sharing protocols, tools and data. As an alternative, decentralized infrastructures have revolutionized the way enterprises, technology and science works. These decentralized infrastructures are composed of loosely connected networks or cells with a common objective and have two things in common. First, all actors adhere to similar standards, making it easy to integrate the resulting outputs. Second, the standards can be applied by a plethora of different actors and implemented in different ways. A classic example is the internet and $\mathrm{p} 2 \mathrm{p}$ networks, which rely on common protocols and standards, but have information distributed across many different nodes, giving robustness to the web. In ecology, we already have pioneer distributed networks performing common experiments globally, such as the NutNet network (Borer et al 2014) or the GrENEnet initiative (https:/ / grenenet.wordpress.com/). We advocate that to advance research on complex global environmental challenges such as pollinator decline, ecologists adopt shared protocols and standards that can be easily replicated in a decentralized way by any researcher. The resulting data can then be integrated to answer global questions. We believe that distributed infrastructures present a compromise between feasibility and usefulness, because they combine the easy implementation 
of locally governed initiatives, with the power of data integration and generality.

Here we review the state of the art regarding long term research infrastructures to (i) describe pollinator decline patterns worldwide, (ii) monitor current pollinator trends, and (iii) understand how to enhance pollinator numbers and pollination in agroecosystems. Next, we discuss how to establish and promote decentralized, but coordinated research infrastructures, in order to accelerate the way we do science and in particular, how we investigate pollinator declines.

\section{Research infrastructures to describe pollinator decline patterns worldwide}

The first step to conserve any taxa is to document past population trends. This includes understanding the worldwide variation in diversity, natural history and historical densities of pollinator populations. In addition, it has been shown that understanding how species interact with other species and with the environment may be more necessary than simply tracking species population trends (Tylianakis et al 2008). Unfortunately, even the most basic taxonomic information is not known for most pollinator groups, specially in some areas, and reconstructing the complex network of species interactions is a daunting task even for the current time period. Despite advances in understanding some species population trends for some areas, overall, the climatic, geographical and sociocultural peculiarities of each region make it difficult to extrapolate results obtained in other regions.

\section{Infrastructures in place}

There are a number of existing infrastructures documenting information about pollinators, but often these are not solely dedicated to pollinators. The first infrastructure needed concerns taxonomic resolution. The Integrated Taxonomic Information System (www.itis.gov) assembles authoritative taxonomic information on plants, animals, fungi, and microbes and the Barcode Of Life Data System (http:// boldsystems.org/) is a cloud-based data storage and analysis platform for DNA-based species identification. Both are key referents on pollinator taxonomic resolution, but is important to highlight that new pollinator species are described every year, and for that reason, the available information is by nature incomplete. The main source of biodiversity information is occurrence records. Much of the available occurrence data, including historical records, have now been centralized in the GBIF (www.gbif.org), but for pollinators, there are still many records curated elsewhere (e.g. www.discoverlife.org, NHM http://data. nhm.ac.uk/dataset/insect-pollinators-initiative, USGS https://npwrc.usgs.gov/pollinator/home, Bees, Wasps and Ants Recording Society (BWARS) http:/ / bwars.com). An important point with this kind of data is that it is able to contain precious information beyond simple occurrence descriptors, as often the collected specimens can provide information on species phenology, species interactions (e.g. what plant were the pollinators visiting) or morphological measures (Bartomeus et al 2018).

\section{Progress made thanks to this infrastructure}

Research using this kind of infrastructure has revealed that bee pollinators are declining, and provided indications about the causes of decline, in temperate zones of northern Europe or the United States (e.g. Bartomeus et al 2013, Scheper et al 2014, Kerr et al 2015), two areas over-represented in terms of research effort. However, despite the increasing availability of historical records, there is still no global assessment of pollinator trends due to the difficulty of using such data (Bartomeus et al 2018). Nevertheless, for some areas, museum specimens have served to document a decline in bee body size (Oliveira et al 2016) or advances in pollinator phenology (Bartomeus et al 2011). Overall, there is an important geographical and taxonomic bias which prevents reaching generality (Archer et al 2014) and despite all these efforts, we know very little for most of the species. Even for Europe, probably the best-studied region in terms of insect pollinator distributions and status, the IUCN Red List assessment of European bees found that $>55 \%$ of EU bee species could not be assessed due to data deficiency (Nieto et al 2014).

\section{The way forward}

To move this field forward, we need more investment in digitizing and making accessible both museum and historical citizen science data (see below for a description of available citizen science datasets). For museums, there are currently several initiatives to crowdsource this endeavour (e.g. https:// notesfromnature.org/; Hill et al 2012), but more funding should be devoted to digitize historical data (Ward et al 2015). While universal central place repositories like GBIF serve as hubs for collecting data, different institutions will inevitably want to host their own data for political or positioning reasons. Hence, we advocate the adoption of common protocols and metadata standards such as the Darwin core (http:// rs.tdwg.org/dwc/; Wieczorek et al 2012) by all data servers to facilitate integration of such data repositories. There are three important ways to facilitate data integration across independent efforts. The first is to ensure data are open and discoverable. This can be achieved by promoting its existence and linking the data to larger projects using persistent identifiers. A second key is to ensure that, regardless of the data collection type, it can be mapped to the same ontologies. Here, the big challenge is to develop tools to jointly analyse diverse data types relating to the same 
concept (e.g. Merow et al 2017). Finally, a key premise to achieve data integration is that open databases use an Application Programming Interface, which allows users to interact with the database programmatically. We envision that tools to query, integrate and clean different databases and read them directly into statistical languages like $\mathrm{R}$ will be the key players to unleash the power of data repositories. The $\mathrm{R}$ open science community (www.ropnsci.org) is already providing tools to query (rgbif; Chamberlain et al 2014), integrate (spocc; Chamberlain 2018) and clean (taxize; Chamberlain and Szöcs 2013) species occurrence data.

\section{Research infrastructures to monitor current pollinator and pollination trends}

The second crucial step to conserve pollinators is to keep monitoring their current trends. Monitoring is a basic tool for conservation as it can be used to detect early warning signals (Dakos and Bascompte 2014) allowing us to act in advance. Contemporary monitoring can also offer new answers by providing data on processes for which we have scarce historical records, such as pollination rates or ecosystem service provision. Thanks to distributed monitoring schemes, for first time ever, ecology may be entering a phase where data availability is not limiting, opening the door to the use of data mining techniques based on prediction, such as machine learning to detect patterns (Hampton et al 2013). We need to move ecology to a more predictive framework to be able to act fast with specific conservation actions, and not be simple accountants of the destruction of life on Earth.

It is worth mentioning that monitoring pollinators is particularly hard because taxonomical identification requires expert knowledge. Given the paucity of taxonomic experts, insect identification has become a major bottleneck. Hence, monitoring of complete community dynamics is a task for specific research projects with specific questions in mind. However, researchers leading these projects can greatly boost the impact of their data by adopting data repository standards that allow easy integration of data across projects. To our knowledge, sharing ecological data in a way that is easy to integrate is hardly possible with the current infrastructures (but see www.mangal.io database; Poisot et al 2016). We have advanced a lot by moving into open data publication policies, and common data repositories like Dryad (https://datadryad. org/) and Figshare (https://figshare.com), but still each dataset has a different format (.xls, .csv, etc...), data are gathered in different units (counts, densities, etc...) and metadata are far from homogeneously documented, making it difficult to unleash the power of such data in a coordinated way.

\section{Infrastructures in place}

The principal aim of the LTER network is to implement long term monitoring, but we do not know of any LTER program specifically monitoring pollinators. However, long term research stations such as the Rocky Mountains Biological Laboratory (RMBL) have been monitoring plants and pollinators opportunistically over the last several decades. In addition, the Group On Earth Observations Biodiversity Observation Network (GEO-BON) was formed in 2014 with the mission to improve the acquisition, coordination and delivery of biodiversity observations and related services to users, including decision makers and the scientific community. GEO-BON does not specifically target pollinators, but it has defined a set of essential biodiversity variables (EBV) to study, report, and manage biodiversity change, focusing on linking monitoring initiatives with decision makers (Pereira et al 2013). Among these EBVs, species interactions, including plant-pollinator interactions, are explicitly considered and there is rapid progress towards enabling large-scale global data products around the EBVs (for an example of this progress on species traits, see Kissling et al 2018).

An alternative approach to monitoring is to use the power of citizen science. Citizen science has a long tradition for some iconic taxa and in some places. For example the Butterfly Monitoring Scheme (Swaay et al 2008) gathers hundreds of volunteers who survey butterflies in a standardized manner in different European countries. Such programs are invaluable, but unfortunately, data from these projects are not always open access, limiting their usability. For other pollinators, data are taxonomically and geographically biased. For example, the BWARS in the UK (www.bwars. $\mathrm{com}$ ) is an amateur naturalists' recording society with a broad taxonomic reach, covering all hymenopteran pollinators, and a long history with records going back over 100 years. eBird (https://ebird.org) gathers observations from bird-watchers around the world and makes the data freely available for researchers (Sullivan et al 2009). This now includes many pollinating species, such as hummingbirds and sunbirds. There is a diversity of smaller citizen science projects targeting specific pollinator guilds or habitats, largely in Europe and the United States, but also elsewhere in the world (see below; IPBES 2016). Finally, the UK Government is currently funding a pollinator monitoring programme as part of the National Pollinator Strategy for England (Carvell et al 2016).

\section{Progress made thanks to this infrastructure}

Data collected at RMBL have documented bumblebee population changes driven by indirect climate effects on floral resources (Ogilvie et al 2017). Researchers have used records from amateur naturalists' organisations such as BWARS or eBird to document major changes in pollinator distributions or phenologies in 
UK, Belgium, the Netherlands and the USA (Biesmeijer et al 2006, Carvalheiro et al 2013, Courter 2017), even incorporating EBVs such as functional traits (Aguirre-Gutiérrez et al 2016). Data provided by butterfly monitoring schemes have been pivotal to documenting butterfly population changes and changes in phenology (Thomas 2005). More recently, citizen science projects have enabled researchers to tackle questions related to urban pollination by describing urban pollinators in the United States (The Great Sunflower Project; www.greatsunflower.org ), changes in urban plant-pollinator interactions in France (Deguines et al 2012; www.spipoll.org) and changes in urban moth densities in the UK (Bates et al 2014; www.gardenmoths.org.uk). There are successful examples of monitoring invasive species in Japan (Bombus terrestris) and Australia (Halictus smaragdulus; Ashcroft et al 2012). Other examples can be found in the Intergovernmental Science Policy Platform on Biodiversity and Ecosystem Services assessment report (IPBES 2016, Table 6.4.6.3).

\section{The way forward}

As a first priority, formal LTER infrastructures targeting pollinators should be established. Ideally pollinator recording schemes targeting easy to identify species can be added upon current monitoring programs in already functioning LTERs using common and standardized protocols, as has been done successfully for butterflies (Swaay et al 2008). Second, GEO-BON has already launched BON in a Box, a customizable online toolkit that lowers the threshold for the start-up of a national, regional or local biodiversity observation system and ensures researchers around the world can build and implement biodiversity observation to international standards. A key challenge is to ensure high uptake of such tools. Third, the power of citizen science has still to explode. Its ability to create infrastructures that integrate data is central to its success in monitoring pollinator trends at large scales. In practice, different organizations will lead local citizen science projects, but it is important that the data recorded are open, as comparable as possible among projects and that basic protocols are shared. Once again, our capacity to discover and integrate the generated decentralized data is the key bottleneck. Analytical tools to integrate heterogeneous data sources will be key in the future. For example, tailored programs that use non-destructive timed counts of target common pollinators representing different taxonomic groups on target plants species and across wide geographical areas can provide invaluable information (Lebuhn et al 2013, but see Kremen et al 2011 for a discussion on citizen science accuracy at recording pollinators). The future also promises exciting tools able to unlock the bottleneck of taxonomic expertise, with the advances of barcoding and cheaper, potentially field-based DNA sequencing techniques like Minion $^{\mathrm{TM}}$ (Brown et al 2017). This technology will allow recording of not only species occurrences, but pollen carryover, pathogens or genetic diversity. As funding for long term monitoring programs is almost non-existent, volunteer based programs have to fulfil the necessary tasks. Coordinating common transferable protocols and data sharing is vital.

\section{Research infrastructures to conserve pollinators and pollination in agroecosystems}

Agricultural ecosystems are productive landscapes, extremely human-modified and heavily managed, but they dominate the global land surface in terms of area (Ellis et al 2010). It is in agroecosystems that pollinators and pollination services have their most quoted monetary values and are potentially the most threatened (Lautenbach et al 2012, Potts et al 2016). Understanding how to conserve pollinators and pollination in such ecosystems requires integrated research efforts that span disciplines and sectors (Dicks et al 2016). Transdisciplinary research develops a common body of knowledge that goes across and beyond disciplines to address a real-world problem (Pohl 2011, Sakao and Brambila-Macias 2018). It often involves non-academic partners such as businesses or policy makers, bringing in new knowledge from outside academic disciplines that helps to frame the problem and develop solutions, so the research itself is genuinely co-produced, co-designed and co-disseminated (Mauser et al 2013). For example, Garibaldi et al (2017) propose a framework for evidence-based assessment of the ecological, social and economic performance of farming systems, centred on a participatory approach to research, involving researchers, farmers and policy makers.

This integrated, transdisciplinary approach is necessary because pollinator decline is a challenging societal problem, with many facets, involving and affecting many societal actors. On one hand, the ecology of pollinators in agroecosystems can only be fully understood in the context of agronomic management, because crops and small managed habitats such as field margins provide essential resources for pollinators. Conversely, the most appropriate management approaches to support pollinators can only be fully understood through research that is well grounded in either economics, or social science disciplines that cover technological innovation, or human or institutional behaviour, so that selected actions are appealing to farmers and a good fit within farming systems. The benefits of pollinators need to be conveyed, and compared among farming systems, in terms of the overall economic and social performance of farms.

A key concept in discussions about transitions to sustainable agriculture is the 'Agricultural Knowledge and Innovation System' (AKIS) (Knierim et al 2015). 
This is the connected network of actors and groups who share and act upon emerging knowledge about agricultural practice, and has been described as a 'linked set of actors that emerges as a result of networking for innovation' (Engel and van den Bor 1995, Labarthe 2009). According to Knierim et al (2015) an AKIS includes five types of service-providing organizations: (i) public sector organizations (ministries and subordinated public administration); (ii) research and education (universities, research institutes, schools), (iii) private sector (industries, independent consultants and advice-providing companies), (iv) farmer-based organizations (chambers of agriculture, cooperatives) and (v) non-governmental organizations (for example, charity organizations, environmental groups). The way these organizations work together, exchange knowledge, and test or develop innovations in a particular agricultural landscape are central to the understanding of agro-ecological approaches to agriculture, or transitions to ecological intensification, which have been identified as key in addressing pollinator decline (Dicks et al 2016). An AKIS thus represents an ideal infrastructure for conducting transdisciplinary research on pollinator decline. The effectiveness of AKISs around the world is likely to be enhanced by decentralized independent networks that are governed locally, but which learn from each other and share outputs.

\section{Infrastructures in place}

There are several examples of successful AKISs, but their structure can follow different strategies. At its core, a functioning, stable AKIS requires (i) national policy support and (ii) co-ordinating structures (Knierim et al 2015). National support can comprise, for instance, a national body that provides agricultural extension services, or a clear national policy in favour of sustainable agriculture. A well-connected network of advisers is an important element of this policy support. The National Pollinators Strategy for England, for example, lays out priority actions to benefit pollinators on farmland, including an action for Government to secure commitment from farm advice providers to give detailed advice on pollinator conservation to farmers. Some European Member States, such as Bavaria and Ireland, have centralised Farm Advisory Services supported through the Rural Development Programme of the Common Agricultura Policy in Europe (Knierim et al 2015). It has been shown that pluralistic advisory services involving public, private and third sector advisors using both centralised and decentralised networks, as found in the UK, can also function well for knowledge exchange and hold substantial social capital (Klerkx and Proctor 2013). However, Labarthe (2009) argues that the trend towards privatisation of extension services seen in France and the Netherlands has weakened links between organisations and is therefore a threat to the multi-actor, collaborative nature of an effective AKIS.

The other key element of AKISs, the coordinating structures, can be institutions that plan and co-ordinate agricultural research and innovation, often working with large networks of farmers. Examples might be the French National Institute for Agricultural Research, or the Brazilian Agricultural Research Corporation (Embrapa). Both are large, Government-funded national networks of agricultural research institutions, decentralized with regional centres specialising in local agricultural systems. National level research networks and structures with a broad focus on agricultural sustainability have also been developed in many countries recently. For example, the Long Term Agro-Ecosystem Research Network is running common experiments across 18 different agricultural landscapes in the USA (Spiegal et al 2018). More specifically considering insects, there has been substantial effort to generate AKIS-type infrastructure globally to develop more sustainable, integrated approaches to control pests while reducing pesticide use (Integrated Pest Management: IPM). Examples include the PURE project, which took a 'co-innovation' approach, based on participatory research methods involving researchers, farmers and farm advisors, to provide IPM solutions and methods for their implementation to reduce pesticide dependence in a selection of major cropping systems in 10 European countries from 2011 to 2015 (Klerkx et al 2017). There is now substantial policy support for IPM at European level, through the Sustainable Use of Pesticides Directive (Directive 2009/ 128/EC), which mandates Member States to promote IPM nationally. Pollination and pest regulation are both ecosystem services important to productive agriculture, delivered by mobile agents (usually, but not exclusively insects) (Kremen et al 2007). Both need to be managed at farm- and landscape scales, with close attention to reducing the use of pesticides and providing appropriate ecological resources for the servicedelivering organisms. It is logical then that research tackling pollinator decline in agricultural ecosystems should operate with the same transdisciplinary infrastructures that have been successfully used for IPM.

\section{Progress made thanks to this infrastructure}

There are some important examples of such coordinated efforts and systems being applied to supporting pollinators and pollination at national or regional level. The Brazilian Pollinators Initiative was started in 2000 by scientists. It became an official Government initiative in 2009, led by the Brazilian Ministry of the Environment, and established research networks focused on 11 valuable crops including cashew, Brazil nut and apple. These networks were funded by the Brazilian Research Council ( $\mathrm{CNPq}$; costing US \$2 million in total) and supported by a range of international institutions (IPBES 2016). They have led to 
important insights such as highlighting the value of natural habitat in supporting pollination of cashew by wild stingless bees, for example (Freitas et al 2014). In the USA, the Land Grant University System, created in the mid-1800s, brings research and extension together within institutions, aiming to provide practical knowledge and information sharing based on unbiased scientific research, to citizens everywhere, both rural and urban (National Research Council 1995). There are several examples of this system enabling excellent transdisciplinary research on pollinators and pollination. These include the Center for Pollinator Research at Penn State University, which has developed a research program around Integrated Pest and Pollinator Management, to integrate pollinator health into IPM (Biddinger and Rajotte 2015). As part of a Darwin Initiative project 'Enhancing the Relationship between People and Pollinators in Eastern India', the Centre for Pollination Studies, based at University of Calcutta, established a field station in the north eastern state of Tripura (http://cpscu.in/) in which researchers worked with a network of local farmers to understand pollinators and pollination. Among other outputs, this project allowed collation of farmer knowledge about the status of pollinators in this region, from which there are no long term monitoring data (Smith et al 2017).

In support of these efforts, the International Pollinators Initiative, facilitated by the Food and Agriculture Association of the United Nations (FAO) from 2000 to 2012, developed a number of tools and guidance documents, including a standard protocol for detecting and measuring pollination deficit in crops tested in at least eighteen countries (Vaissiere et al 2011), and a guide to help farmers evaluate the costs and benefits of applying pollinator-friendly practices (Grieg-Gran and Gemmill-Herren 2012). The standardized protocol for pollination deficit resulted in a seminal publication on the potential to enhance crop yields by enhancing wild pollinator diversity globally (Garibaldi et al 2016). Within GEO-BON, the Ecosystem Services Working Group is developing a set of 'Essential Ecosystem Service Variables', to enable standardised quantification of the natural and social systems that form the basis for ecosystem service provision at a range of scales, including trade-offs and a wide range of social dimensions.

\section{The way forward}

We propose that independent, relatively localised networks of farmers, advisers, researchers, policy makers, businesses and NGOs become a standard approach for research into understanding and mitigating against pollinator decline in agricultural (and perhaps also urban) contexts, following a co-innovation model of transdisciplinary research, such as in the examples discussed above. Our proposal is based on the clear success of sub-national IPM projects around the world (Pretty 2005, Klerkx et al 2017), and the observation that decentralised pluralistic farm advisory systems can function well for knowledge exchange (Klerkx and Proctor 2013). The ideal structure involves a diversity of actors and approaches, but uses standardized protocols and variables wherever possible (see for example FAO protocols above) so that results can be shared among AKIS and integrated globally for broad analysis. This requires standardized protocols to be widely available, with a global awareness-raising effort so that any group convened to address pollinator decline anywhere in the world knows about them from the outset.

\section{The great challenge ahead: unity in diversity}

A common theme while reviewing the current research infrastructures to tackle the issue of pollinator declines is the difficulty of integrating data gathered by different institutions, researchers, or monitoring programs. Currently, research infrastructures are led by a mix of institutions, governmental agencies and large independent initiatives. This diversity ensures that a range of points of views is represented and that tailored data protocols are in place to answer different questions. But it comes at a cost. Integrating the knowledge among those infrastructures is not always easy, and integrating datasets across the plethora of potential data providers, including researchers, NGOs, naturalists or farmers is hardly possible. Hence, we are at risk of providing disconnected bits of information, spreading research effort across a multitude of case studies and ending up knowing 'very little about everything', rather than being able to connect the dots and see how patterns emerge.

As a complement to centralized research infrastructures, we advocate for creating decentralized infrastructures that allow collating distributed experiments and observations by different actors. The task is not easy, because it requires the use of standard protocols largely accepted by the global community. Luckily, these protocols are already available (e.g. FAO) and others can be adapted. A nice example of a distributed experiment is the NutNet project, which integrates a distributed experiment globally (Borer et al 2013). For pollinators, such experiments should be easy to perform by reporting occurrence data, visitation rates to plants or pollination success using common protocols. In fact, this kind of data exists in large amounts, but usually based on non-comparable methods. The price of collating the existing data is prohibitive as it requires contacting each researcher or organization individually, or navigating the supplementary materials of dozens of articles. Hence, the key challenges are to report these data in a way that is open, associated to standardized metadata and discoverable, and to create tools that allow the integration of heterogeneous collection 
protocols. We envision a key role of ecoinformatics in bridging this gap. As a community, it would be a huge step forward to create comparable protocols and experiments by consensus that can be adopted by any researcher or citizen science project and collected in central places. A big step towards this would be for journals to stop putting the emphasis on the novelty of methods and to favour papers using robust standard and comparable protocols with comparable sampling efforts and methods. In a nutshell, we need to foster decentralized independent research infrastructures that can easily be brought together at larger scales when necessary.

\section{Acknowledgments}

We thank the FUNCIBIO consortium for stimulating some of this ideas. IB is funded by project EU-MSCCIG BeeFun (PCIG14-GA-2013-631653) and Biodiversa-Belmont Forum OBServ (PCI2018-093171), and Lynn Dicks is funded by the Natural Environment Research Council (NERC; Grant Code NE/ N014472/1).

\section{ORCID iDs}

Ignasi Bartomeus (10) https://orcid.org/0000-00017893-4389

\section{References}

Aguirre-Gutiérrez J, Kissling W D, Carvalheiro L G, WallisDeVries M F, Franzén M and Biesmeijer J C 2016 Functional traits help to explain half-century long shifts in pollinator distributions Sci. Rep. 624451

Aizen M A et al 2019 Coordinated species importation policies are needed to reduce serious invasions globally: the case of alien bumblebees in South America J. Appl. Ecol. 56 100-6

Archer C R, Pirk C W W, Carvalheiro L G and Nicolson S W 2014 Economic and ecological implications of geographic bias in pollinator ecology in the light of pollinator declines Oikos 123 401-7

Ashcroft M B, Gollan J R and Batley M 2012 Combining citizen science, bioclimatic envelope models and observed habitat preferences to determine the distribution of an inconspicuous, recently detected introduced bee (Halictus smaragdulus Vachal Hymenoptera: Halictidae) in Australia Biol. Invasions 14 515-27

Bartomeus I, Ascher J S, Gibbs J, Danforth B N, Wagner D L, Hedtke S M and Winfree R 2013 Historical changes in northeastern US bee pollinators related to shared ecological traits Proc. Natl Acad. Sci. USA $1104656-60$

Bartomeus I, Ascher J S, Wagner D, Danforth B N, Colla S, Kornbluth S and Winfree R 2011 Climate-associated phenological advances in bee pollinators and bee-pollinated plants Proc. Natl Acad. Sci. USA 108 20645-9

Bartomeus I, Stavert J, Ward D and Aguado O 2018 Historic collections as a tool for assessing the global pollinator crisis Phil. Trans. R. Soc. B 37420170389

Bates A J et al 2014 Garden and landscape-scale correlates of moths of differing conservation status: significant effects of urbanization and habitat diversity PLoS One 9 e86925
Biddinger D J and Rajotte E G 2015 Integrated pest and pollinator management-adding a new dimension to an accepted paradigm Curr. Opin. Insect Sci. 10 204-9

Biesmeijer J C et al 2006 Parallel declines in pollinators and insectpollinated plants in Britain and the Netherlands Science 313 351-4

Borer E T, Harpole W S, Adler P B, Lind E M, Orrock J L, Seabloom E W and Smith M D 2014 Finding generality in ecology: a model for globally distributed experiments Methods Ecol. Evol. 565-73

Brown B L, Watson M, Minot S S, Rivera M C and Franklin R B 2017 MinION $^{\mathrm{TM}}$ nanopore sequencing of environmental metagenomes: a synthetic approach GigaScience 6 1-0

Cameron S A, Lozier J D, Strange J P, Koch J B, Cordes N, Solter L F and Griswold T L 2011 Patterns of widespread decline in North American bumble bees Proc. Natl Acad. Sci. $108662-7$

Carvalheiro L G et al 2013 Species richness declines and biotic homogenisation have slowed down for NW-European pollinators and plants Ecol. Lett. 16 870-8

Carvell C 2016 Design and testing of a national pollinator and pollination monitoring framework Final Summary Report to the Department for Environment Project WC1101 Food and Rural Affairs (Defra), Scottish Government and Welsh Government

Chamberlain S 2018 SPOCC: interface to species occurrence data sources. R package version 0.7.0.

Chamberlain S, Ram K, Barve V and Mcglinn D 2014 RGBIF: Interface to the Global Biodiversity Information Facility API. R package version 0.77

Chamberlain S A and Szöcs E 2013 Taxize: taxonomic search and retrieval in R. F1000Research.2

Courter J R 2017 Changes in spring arrival dates of rufous hummingbirds (Selasphorus rufus) in Western North America in the past century Wilson J. Ornithol. 129 535-44

Dakos V and Bascompte J 2014 Critical slowing down as early warning for the onset of collapse in mutualistic communities Proc. Natl Acad. Sci. 111 17546-51

Deguines N, Julliard R, De Flores M and Fontaine C 2012 The whereabouts of flower visitors: contrasting land-use preferences revealed by a country-wide survey based on citizen science PLoS One 7 e 45822

Dicks L V et al 2016 Ten policies for pollinators Science 354 975-6

Ellis E C, Klein Goldewijk K, Siebert S, Lightman D and Ramankutty N 2010 Anthropogenic transformation of the biomes, 1700 to 2000 Glob. Ecol. Biogeogr. 19589-606

Engel P G and van den Bor W 1995 Agricultural education from a knowledge systems perspective: from teaching to facilitating joint inquiry and learning Eur. J. Agric. Educ. Extension 1 1-23

Freitas B M et al 2014 Forest remnants enhance wild pollinator visits to cashew flowers and mitigate pollination deficit in NE Brazil J. Pollination Ecol. 12 22-30

Garibaldi L A, Gemmill-Herren B, D’Annolfo R, Graeub B E, Cunningham S A and Breeze T D 2017 Farming approaches for greater biodiversity, livelihoods, and food security Trends Ecol. Evol. 32 68-80

Garibaldi L A et al 2013 Wild pollinators enhance fruit set of crops regardless of honey bee abundance Science 339 1608-11

Garibaldi L A et al 2016 Mutually beneficial pollinator diversity and crop yield outcomes in small and large farms Science 351 388-91

Goulson D, Nicholls E, Botías C and Rotheray E L 2015 Bee declines driven by combined stress from parasites, pesticides, and lack of flowers Science 3471255957

Grieg-Gran W and Gemmill-Herren B 2012 Handbook for Participatory Socioeconomic Evaluation of Pollinator-Friendly Practices. (Rome: Food and Agricultural Organization of the United Nations)

Hampton S E, Strasser C A, Tewksbury J J, Gram W K, Budden A E, Batcheller A L, Duke C S and Porter J H 2013 Big data and the future of ecology Frontiers Ecol. Environ. 11 156-62 
Hill A et al 2012 The notes from nature tool for unlocking biodiversity records from museum records through citizen science Zookeys. 209 219-33

IPBES 2016 The Assessment Report of the Intergovernmental SciencePolicy Platform on Biodiversity and Ecosystem Services on Pollinators, Pollination and Food Production (Bonn: IPBES)

Kennedy C M et al 2013 A global quantitative synthesis of local and landscape effects on wild bee pollinators in agroecosystems Ecol. Lett. 16 584-99

Kerr J T et al 2015 Climate change impacts on bumblebees converge across continents Science 349 177-80

Kissling W D et al 2018 Towards global data products of essential biodiversity variables on species traits Nat. Ecol. Evol. 2 1531-40

Klein A M, Vaissiere B E, Cane J H, Steffan-Dewenter I, Cunningham S A, Kremen C and Tscharntke T 2007 Importance of pollinators in changing landscapes for world crops Proc. R. Soc. B 274 303-13

Klerkx L and Proctor A 2013 Beyond fragmentation and disconnect: networks for knowledge exchange in the English land management advisory system Land Use Policy 30 13-24

Klerkx L, Seuneke P, de Wolf P and Rossing W A H 2017 Replication and translation of co-innovation: the influence of institutional context in large international participatory research projects Land Use Policy 61 276-92

Knierim A, Boenning K, Caggiano M, Cristóvão A, Dirimanova V, Koehnen T, Labarthe P and Prager K 2015 The AKIS concept and its relevance in selected EU member states Outlook Agric. $4429-36$

Kremen C, Ullman K S and Thorp R W 2011 Evaluating the quality of citizen-scientist data on pollinator communities Conservation Biol. 25 607-17

Kremen Cet al 2007 Pollination and other ecosystem services produced by mobile organisms: a conceptual framework for the effects of land-use change Ecol. Lett. 10 299-314

Labarthe P 2009 Extension services and multifunctional agriculture. Lessons learnt from the French and Dutch contexts and approaches J. Environ. Manage. 90 S193-202

Lautenbach L S, Seppelt R, Liebscher J and Dormann C F 2012 Spatial and temporal trends of global pollination benefit PLoS One 7 e35954

Lebuhn Get al 2013 Detecting insect pollinator declines on regional and global scales Conservation Biol. 27 113-20

Mauser W, Klepper G, Rice M, Schmalzbauer B S, Hackmann H, Leemans R and Moore H 2013 Transdisciplinary global change research: the co-creation of knowledge for sustainability Curr. Opin. Environ. Sustain. 5 420-31

Merow C, Wilson A M, Jetz W and Peres-Neto P 2017 Integrating occurrence data and expert maps for improved species range predictions Glob. Ecol. Biogeogr. 26 243-58

National Research Council 1995 Colleges of Agriculture at the Land Grant Universities: A Profile. (Washington, DC: The National Academies Press) 168p

Nieto A et al 2014 European red list of bees. Luxembourg: Publication Office of the European Union 98

Ogilvie J E, Griffin S R, Gezon Z J, Inouye B D, Underwood N, Inouye D W and Irwin R E 2017 Interannual bumble bee abundance is driven by indirect climate effects on floral resource phenology Ecol. Lett. 20 1507-15

Oliveira M O, Freitas B M, Scheper J and Kleijn D 2016 Size and sexdependent shrinkage of Dutch bees during one-and-a-half centuries of land-use change PLoS One 11 e0148983

Ollerton J 2017 Pollinator diversity: distribution, ecological function, and conservation Annu. Rev. Ecol., Evol. Systematics $48353-76$
Ollerton J, Winfree R and Tarrant S 2011 How many flowering plants are pollinated by animals? Oikos 120 321-6

Pereira H M et al 2013 Essential biodiversity variables Science 339 $277-8$

Pohl C 2011 What is progress in transdisciplinary research? Futures $43618-26$

Poisot T, Baiser B, Dunne J A, Kéfi S, Massol F, Mouquet N, Romanuk T N, Stouffer D B, Wood S A and Gravel D 2016 Mangal-making ecological network analysis simple Ecography 39 384-90

Potts S G et al 2016 Safeguarding pollinators and their values to human well-being Nature 540220

Pretty J 2005 Sustainability in agriculture: recent progress and emergent challenges Issues Environ. Sci. Technol. 21 1-15

Rader R et al 2016 Non-bee insects are important contributors to global crop pollination Proc. Natl Acad. Sci. 113 146-51

Ratto F, Simmons B I, Spake R, Zamora-Gutierrez V, MacDonald M A, Merriman J C, Tremlett C J, Poppy G M, Peh K S and Dicks L V 2018 Global importance of vertebrate pollinators for plant reproductive success: a meta-analysis Frontiers Ecol. Environ. 16 82-90

Rundlöf M et al 2015 Seed coating with a neonicotinoid insecticide negatively affects wild bees Nature $52177-80$

Sakao T and Brambila-Macias S A 2018 Do we share an understanding of transdisciplinarity in environmental sustainability research? J. Cleaner Prod. 170 1399-403

Scheper J, Reemer M, van Kats R, Ozinga W A, van der Linden G T, Schaminée J H, Siepel H and Kleijn D 2014 Museum specimens reveal loss of pollen host plants as key factor driving wild bee decline in The Netherlands Proc. Natl Acad. Sci. $11117552-7$

Smith B M, Chakrabarti P, Chatterjee A, Chatterjee S, Dey U K, Dicks L V, Giri B, Laha S, Majhi R K and Basu P 2017 Collating and validating indigenous and local knowledge to apply multiple knowledge systems to an environmental challenge: A case-study of pollinators in India Biol. Conservation $21120-8$

Spiegal S et al 2018 Evaluating strategies for sustainable intensification of US agriculture through the long-term agroecosystem research network Environ. Res. Lett. 1303403

Sullivan B L, Wood C L, Iliff M J, Bonney R E, Fink D and Kelling S 2009 eBird: a citizen-based bird observation network in the biological sciences Biol. Conservation 142 2282-92

Swaay C A, van, Nowicki P, Settele J and Strien AJ van 2008 Butterfly monitoring in Europe: methods, applications and perspectives Biodiversity Conservation 17 3455-69

Thomas J A 2005 Monitoring change in the abundance and distribution of insects using butterflies and other indicator groups Phil. Trans. R. Soc. B $360339-57$

Tylianakis J M, Didham R K, Bascompte J and Wardle D A 2008 Global change and species interactions in terrestrial ecosystems Ecol. Lett. 11 1351-63

Vaissiere B E, Freitas B M and Gemmill-Herren B 2011 Protocol to Detect and Assess Pollination Deficit in Crops: A Handbook for its Use (Rome: Food and Agricultural Organization of the United Nations)

Ward D F, Leschen R A and Buckley T R 2015 More from ecologists to support natural history museums Trends Ecol. Evol. 30 373-4

Wieczorek J et al 2012 Darwin core: an evolving communitydeveloped biodiversity data standard PLoS One 7 e29715

Winfree R, Bartomeus I and Cariveau D P 2011 Native pollinators in anthropogenic systems Annu. Rev. Ecol. Systematics 42 1-21 